\title{
High Folic Acid Intake Reduces Natural Killer Cell Cytotoxicity in Aged Mice ${ }^{\Im}$
}

Hathairat Sawaengsri ${ }^{1}$, Junpeng Wang ${ }^{1,2}$, Christina Reginaldo ${ }^{1}$, Josiane Steluti ${ }^{1,3}$, Dayong Wu ${ }^{1}$, Simin Nikbin Meydani ${ }^{1}$, Jacob Selhub ${ }^{1}$, Ligi Paul ${ }^{1 *}$

${ }^{1}$ Jean Mayer USDA Human Nutrition Research Center on Aging at Tufts University, Boston, MA 02111

${ }^{2}$ Translational Medical Center of Huaihe Clinical College, Henan University, Kaifeng 475000, China

${ }^{3}$ Present address. Department of Nutrition, School of Public Health, University of Sao Paulo, Sao Paulo, Brazil, 01246-904

*To whom correspondence should be addressed. Jean Mayer USDA Human Nutrition Research Center on Aging at Tufts University, 711 Washington Street, Boston, MA 02111. Phone: +1 617-556-3141. Fax: +1 617-556-3166. Email: Ligi.Paul_Pottenplackel@tufts.edu ${ }^{25}$ Conflict of interest: The authors declare no conflict of interest

Running title: High folic acid diet \& natural killer cell cytotoxicity

Support from United States Department of Agriculture Specific Cooperative Agreement \#581950-0-014 and pilot grant from Jean Mayer USDA Human Nutrition Research Center on Aging at Tufts University. Any opinions, findings, conclusion, or recommendations expressed in this publication are those of the authors and do not necessarily reflect the view of the United States Department of Agriculture.

Keywords: Folic acid, folate, natural killer cell cytotoxicity, interleukin-10. 


\begin{abstract}
Presence of unmetabolized folic acid in plasma, which is indicative of folic acid intake beyond the metabolic capacity of the body, is associated with reduced natural killer (NK) cell cytotoxicity in post-menopausal women $\geq 50$ years. NK cells are cytotoxic lymphocytes that are part of the innate immune system critical for surveillance and defense against virus-infected and cancer cells. We determined if a high folic acid diet can result in reduced NK cell cytotoxicity in an aged mouse model. Female C57BL/6 mice (16-month-old) were fed an AIN-93M diet with the recommended daily allowance (1x RDA, control) or 20x RDA (high) folic acid for 3 months. NK cytotoxicity was lower in splenocytes from mice fed a high folic acid diet when compared to mice on control diet $(\mathrm{P}<0.04)$. The lower NK cell cytotoxicity in high folic acid fed mice could be due to their lower mature cytotoxic /naïve NK cell ratio $(\mathrm{P}=0.03)$ when compared to the control mice. Splenocytes from mice on high folic acid diet produced less interleukin (IL)-10 when stimulated with lipopolysaccharide $(\mathrm{P}<0.05)$. The difference in $\mathrm{NK}$ cell cytotoxicity between dietary groups was abolished when the splenocytes were supplemented with exogenous IL-10 prior to assessment of the NK cytotoxicity, suggesting that the reduced NK cell cytotoxicity of the high folic acid group was at least partially due to reduced IL-10 production. This study demonstrates a causal relationship between high folic acid intake and reduced NK cell cytotoxicity and provides some insights into the potential mechanisms behind this relationship.
\end{abstract}

Keywords: Folic acid, folate, natural killer cell cytotoxicity, interleukin-10. 


\section{Introduction}

Recent human and animal studies have shown that intake of excess folic acid has been linked to a variety of negative health outcomes, including increased risk for cancer, insulin resistance, allergies, behavior modification and birth defects [1-4]. Folic acid, the synthetic form of the vitamin folate (B9) is used in supplements and fortified cereal products due to its stability when compared to other forms of folate. The recommended daily allowance (RDA) for folate is $400 \mu \mathrm{g}$ dietary folate equivalents, which is equal to $400 \mu \mathrm{g}$ natural folate or $240 \mu \mathrm{g}$ folic acid [5, 6]. Approximately $35 \%$ of the US population consumes folic acid containing dietary supplements and $5 \%$ exceed the tolerable upper intake level of $1000 \mu \mathrm{g} / \mathrm{d}$ for folic acid [7]. Many B-vitamin supplementation trials focusing on age-related chronic illnesses use doses of folic acid at 5000 $\mu \mathrm{g} / \mathrm{d}$ or higher [8-11] which is approximately 20 fold the RDA or more. Women who are at risk for neural tube defect pregnancies are recommended to take 4000-5000 $\mu \mathrm{g}$ folic acid/d [12-14]. Folic acid must be reduced by dihydrofolate reductase (DHFR) to tetrahydrofolate before it can enter the metabolic pathway. In humans, DHFR is a slow enzyme with poor affinity for folic acid [15]. In addition, genetic variations in DHFR also influence the ability of an individual to metabolize folic acid [16]. We have previously shown that the presence of unmetabolized folic acid in plasma, indicative of folic acid intake beyond the metabolic capacity of the body, is associated with reduced natural killer (NK) cell cytotoxicity in postmenopausal women aged 5075 years [17]. NK cells are cytotoxic lymphocytes that are part of the innate immune system and are important for surveillance and defense against virus-infected and cancer cells. They bind to target cells and perforate the cell membrane by secreting pore-forming protein perforin and trigger apoptosis by secreting granzymes [18]. Low NK cytotoxicity is associated with increased risk for cancer in humans [19]. Hence it is important to determine if there is a causal relationship between high folic acid intake and NK cytotoxicity.

\section{Materials and Methods}




\subsection{Animals and diets.}

All animal procedures were approved by the Institutional Animal Care and Use Committee of the Jean Mayer USDA Human Nutrition Research Center on Aging at Tufts University and conducted according to the Guide for the Care and Use of Laboratory Animals (1996). Sixteenmonth-old female C57BL/6 mice were purchased from National Institute of Aging colonies at Charles River Breeding Laboratories (Wilmington, MA). We sought to determine the effect of high folic acid intake on immune function in an aged mouse model since the initial observation was reported in a study of women 50 years and older [17]. The mice were housed on a 12 hour light/dark cycle and provided free access to the diets throughout the experiment. Twelve mice per diet group were maintained on an AIN-93M [20] based diet (Harlan-Teklad, Madison, WI) with the American Institute of Nutrition recommended daily allowance of $2 \mathrm{mg} / \mathrm{kg}$ diet folic acid (control diet, 1x RDA) or $40 \mathrm{mg} / \mathrm{kg}$ diet folic acid (high folic acid diet, 20x RDA) for 3 months. The dosage of folic acid in the high folic acid diet was determined based on a previous study that investigated the effect of high folic acid diet in mice [21]. In addition, equivalent dosage of folic acid is used in many intervention trials of age-related chronic illnesses [8, 9].

\subsection{Spleen cell isolation.}

Mice were euthanized by $\mathrm{CO}_{2}$ asphyxiation followed by exsanguination through cardiac puncture, and blood was used for plasma isolation. Spleen was removed aseptically and singlecell suspensions were prepared as previously described [22]. Spleens were placed in sterile RPMI 1640 medium (Lonza, MA) which was supplemented with 5\% heat inactivated fetal bovine serum, $25 \mathrm{mmol} / \mathrm{L}$ HEPES, $2 \mathrm{mmol} / \mathrm{L}$ glutamine, $100 \mathrm{kU} / \mathrm{L}$ penicillin, and $100 \mathrm{mg} / \mathrm{L}$ streptomycin (Life Technologies, CA) and disrupted between two sterile frosted glass slides. The cells were collected by centrifugation at $300 \mathrm{G}$ for $10 \mathrm{~min}$ and resuspended in red blood cell lysis buffer (Sigma, MO) to lyse red blood cells. After washing with phosphate buffered saline and removing cell debris by filtering through $40 \mu \mathrm{M}$ nylon cell strainer (BD Pharmingen), 
splenocytes were counted using an Accuri C6 flow cytometer (BD Accuri Cytometers, MI) and resuspended in appropriate media for the assays.

\subsection{Preparation of target cells.}

YAC-1 cells, a murine T- lymphoma cell line sensitive to NK cell killing, were grown in complete RPMI 1640 medium prepared as above and maintained at $37^{\circ} \mathrm{C}$ in $5 \% \mathrm{CO}_{2}$. For the 5 days before the assay, cells were subcultured every $24 \mathrm{~h}$ to ensure that they were in the $\log$ phase. The cells used for the assay were stained with $10 \mathrm{nM}$ of carboxyfluorescein succinimidyl ester (CFSE, eBioscience, CA) for 10 minutes at room temperature in the dark, washed twice in phosphate buffered saline with $2 \%$ heat-inactivated fetal bovine serum and resuspended to a final concentration of $10^{6}$ cells/mL in RPMI 1640 medium.

\subsection{NK cytotoxicity assay.}

The flow cytometric assay described by McGinnes et al [23] was used with modifications as described by Cao et al. [24]. All reagents were purchased from eBioscience. Splenocytes $\left(10^{7} /\right.$ tube) were stained with allophycocyanin (APC)-conjugated anti-CD3 antibody and phycoerythrin (PE)-conjugated anti-NK1.1 antibody to identify NK cells (CD3 ${ }^{-} \mathrm{NK} 1.1^{+}$). Stained splenocytes were then incubated with CFSE-labelled YAC-1 cells (target cells) at effector-to-target (E:T) cell ratios of 100:1, 50:1, 25:1, and 12.5:1 for $3 \mathrm{~h}$ at $37 \mathrm{C}$ with $5 \% \mathrm{CO}_{2}$. After the incubation was complete, 7-amino-actinomycin D (7-AAD) was added to each tube to a final concentration of $1.11 \mu \mathrm{g} / \mathrm{mL}$. Dead YAC-1 cells, which were identified as 7-AAD and CFSE double positive cells, were counted using an Accuri C6 flow cytometer and acquired data were analyzed with FlowJo 7.6 software (Treestar Inc., OR). CFSE stained YAC-1 cells incubated in the absence of splenocytes were used to determine spontaneously dead target cells. Percent specific target cell death (cytotoxicity) was then expressed as: 100 x $\{$ [dead YAC-1 Cells $(\%)$ - spontaneously dead YAC-1 Cells (\%)]/ [100 - spontaneously dead YAC-1 target cells $(\%)]\}$. 


\subsection{Immunophenotyping.}

Splenocyte populations were determined using flow cytometry. Splenocytes were blocked using anti-CD16/32 antibodies and then stained using the following fluorochrome-conjugated antibodies: PE or APC-anti-CD3, APC-anti-CD4, fluorescein isothiocyanate (FITC) anti-CD8 and PE-anti-NK1.1 (eBioscience), to identify all T cells $\left(\mathrm{CD} 3^{+}\right)$, T-helper cells $\left(\mathrm{CD} 3^{+} \mathrm{CD} 4^{+}\right)$, cytotoxic T cells $\left(\mathrm{CD}^{+} \mathrm{CD}^{+}\right)$, NK cells $\left(\mathrm{CD}^{-} \mathrm{NK}^{-} 1^{+}\right)$and natural killer T (NKT) cells which have the properties of both T cells and NK cells $\left(\mathrm{CD}^{+} \mathrm{NK} 1.1^{+}\right)$. The stained cells were then analyzed using Accuri C6 flow cytometer and acquired data analyzed with FlowJo 7.6 to determine the immune cell phenotype.

Natural killer cell subsets were identified as previously described [25] using the following fluorochrome conjugated antibodies: APC-anti-CD3, PE-anti-NK1.1, FITC-anti-CD27 and PerCP-Cy5.5-anti-CD11b. All staining reactions included isotype controls to detect non-specific background signals. The antibodies and the respective isotype controls were purchased from eBioscience. The stained cells were analyzed using an Accuri C6 flow cytometer and the data were analyzed with FlowJo 7.6. Since a small portion of spleen was removed for folate analysis and the remaining spleen was immediately aseptically transferred to cell culture medium without weighing, the absolute numbers of the various cell types in spleen were not determined. Populations of various cell types were instead determined as percentage of total splenocytes.

\subsection{Cytokine production.}

Splenocytes in complete RPMI 1640 medium were stimulated in separate reactions with bacterial lipopolysaccharide (LPS, $1 \mu \mathrm{g} / \mathrm{mL})$ for $24 \mathrm{~h}$, concanavalin A (Con A) $(1.5 \mu \mathrm{g} / \mathrm{mL})$, or anti-CD28 antibody $(1 \mu \mathrm{g} / \mathrm{mL})$ and anti-CD3 antibody $(5 \mu \mathrm{g} / \mathrm{mL})$ coated on cell culture plates for 48 hours . At the end of the incubation, cell-free supernatants were collected and stored at $-80^{\circ} \mathrm{C}$ until analysis. The concentration of interleukin (IL)-6, IL-10, tumor necrosis factor (TNF)- $\alpha$, monocyte chemoattractant protein (MCP)-1, and interferon (IFN)- $\gamma$ in the supernatants from LPS 
stimulated cells, and the concentration of IFN- $\gamma$, IL-2, IL-4, IL-6, IL-10, IL-17A, and TNF- $\alpha$ in the supernatants of Con A or anti-CD3and anti-CD28 stimulated cells were determined using the mouse cytometric bead array kit according to the manufacturer's instructions (CBA; BD Biosciences, CA). The fluorescence signals associated with cytokine-bead complex were acquired using Accuri C6 flow cytometer, and data were analyzed using FCAP Array ${ }^{\mathrm{TM}}$ Software 3.0.1 (CBA; BD Biosciences).

\subsection{Stimulation of NK cytotoxicity by $I L-10$.}

Splenocytes $\left(6 \times 10^{6} /\right.$ well) were incubated with recombinant mouse IL-10 (eBioscience) at a final concentration of $15 \mathrm{ng} / \mathrm{mL}$ for 15 hours before measuring $\mathrm{NK}$ cytotoxicity as described above for the E:T ratios 25:1 and 12.5:1.

\subsection{Folate analysis.}

Total folate from spleen was determined using a microbial assay with Lactobacillus casei [26]. Protein concentration of the spleen extract used for folate assay was determined by Bradford method [27] using Bio-Rad protein assay reagent (Bio-Rad, CA). Folate forms in nonfasting plasma samples were analyzed by HPLC-affinity chromatography with electrochemical detection [28].

\subsection{Statistical analyses.}

Results are expressed as means \pm SEM. One way ANOVA was used for the effect of diet on NK cell cytotoxicity adjusted for day of experiment. Student's t-test was used for all other continuous outcomes. Significance was determined at $\mathrm{P}<0.05$. Statistical analysis was performed using SAS $9.3(\mathrm{NC})$.

\section{Results}

\subsection{Effect of high folic acid diet on tissue and plasma folate content.}


Animals on both control and high folic acid diets gained weight during the 3 months on experimental diets, but there was no difference between the two diet groups in weight gain (data not shown). Analysis of non-fasting plasma showed that mice on high folic acid diet had significantly higher concentration of unmetabolized folic acid, methyl tetrahydrofolate and formylated tetrahydrofolate when compared to mice on the control diet (Fig. 1A). Since the NK cell cytotoxicity was determined using splenocytes, we also determined the folate concentration of spleen. Mice fed a high folic acid diet had a higher concentration of total folate in spleen when compared to those on the control diet $(18.21 \pm 0.76 \mathrm{vs} 12.38 \pm 0.96 \mathrm{ng}$ folate $/ \mathrm{mg}$ protein, $\mathrm{P}<0.01$, Fig. 1B).

\subsection{Effect of high folic acid diet on NK cell cytotoxicity.}

The mean NK cell cytotoxicity of mice fed a high folic acid diet was significantly lower than that of the mice fed the control diet at effector to target cell ratios of 25:1 $(\mathrm{P}=0.03)$ and 12.5:1 $(\mathrm{P}=0.04)$ by $14 \%$ and $23 \%$ respectively (Fig. 2). We determined if the difference in NK cell cytotoxicity of the mice on the two diets was due to differences in the percentage of NK cells. Since the NK cell cytotoxicity assay measures the activity of both NK and NKT cells, we also measured the percentage of NKT cells in the spleen. While the percentage of NK cells in the spleen was lower in the high folic acid group compared to the control group, the difference was not statistically significant ( $\mathrm{P}=0.15)$ (Fig. 3). The percentage of NKT cells in spleen was similar in both diet groups (Fig. 3). The percentages of T helper cells and cytotoxic T-cells in total spleen cells were also similar in both diet groups (Supplementary Fig. 1).

\subsection{Effect of high folic acid diet on NK cell subsets}

We determined the population of NK subsets in both diet groups based on the presence of the surface markers CD11b and CD27 [29]. Double negative (DN, CD11b ${ }^{-}$CD27) cells are NK cell precursors without effector function, $\mathrm{CD} 11 \mathrm{~b}^{-} \mathrm{CD} 27^{+}$(R1 subset) are naïve and have reduced effector functions, $\mathrm{CD} 11 \mathrm{~b}^{+} \mathrm{CD} 27^{+}$(R2 subset) are considered mature NK cells capable of killing 
target cells and secreting cytokines, and $\mathrm{CD}_{11} \mathrm{~b}^{+} \mathrm{CD} 27^{-}$(R3 subset) are terminally differentiated, mature NK cells that predominantly secretes cytokines [25, 29-31]. In mice fed a high folic acid diet there was a trend for a lower percentage of mature R2 NK cells $(\mathrm{P}=0.08)$ and higher percentage of naïve $\mathrm{R} 1$ cells $(\mathrm{P}=0.08)$ when compared to the control group (Fig. 4A). The percentage of DN and R3 NK cells was similar in both diet groups (Fig. 4A). The ratio of R2 to R1 NK cells ( $\mathrm{P}=0.03)$, but not that of R3 to R1 was significantly lower in the high folic acid fed mice when compared to those on the control diet (Fig. 4B).

\subsection{Effect of high folic acid diet on cytokine production by splenocytes}

Since the percentage of NK cells and activation are dependent on cytokines we determined the production of cytokines (IL-10, IFN- $\gamma$, IL-6, TNF- $\alpha$ ) and chemokine (MCP-1) by splenocytes after LPS stimulation. LPS stimulated a wide array of cell types in the splenocytes. The production of IL-10 by splenocytes from the animals in the high folic acid group were lower than that of the control group $(\mathrm{P}<0.05)$ (Fig. 5). The production of other cytokines was not different between the two diet groups. To determine if the low IL-10 production contributes to the reduced NK cell cytotoxicity in the high folic acid fed mice we stimulated the splenocytes with recombinant IL-10 prior to the NK cell cytotoxicity assay. After stimulation with IL-10, the NK cell cytotoxicity of the high folic acid group was similar to that of the control group (Fig. 6). When only the T cells among the splenocytes were specifically activated with Con A or antibodies against CD3 and CD28, there was no difference in the production of cytokines IFN- $\gamma$, IL-2, IL-4, IL-6, IL-10, IL-17A, and TNF- $\alpha$ between the 2 diet groups (Supplementary Fig. 2A and $2 \mathrm{~B})$.

\section{Discussion}

In this study, we established a causal effect of high folic acid intake on lower NK cell cytotoxicity in mice. Intake of a high folic acid diet resulted in up to $23 \%$ lower NK cell cytotoxicity in splenocytes of aged mice when compared to consumption of recommended dose 
of folic acid ( $\mathrm{P}<0.04)$ (Fig. 2). This supports our earlier finding that folic acid intake in excess of the metabolic capacity of the body, as indicated by unmetabolized folic acid in plasma, is associated with lower NK cell cytotoxicity in postmenopausal women [17]. In aged mice, a high folic acid diet increased the concentration of total folate in spleen tissue, as well as the concentrations of unmetabolized folic acid, methyl tetrahydrofolate and formyl tetrahydrofolate in plasma when compared to control diet (Fig. 1). We measured the plasma folate concentrations under non-fasting rather than fasting conditions to determine the extent to which the mice are exposed to the various folate forms after consuming the experimental diet. The concentrations of unmetabolized folic acid in mice fed a high folic acid diet were comparable to what was observed in post-prandial serum of human subjects after consumption of $1000 \mu \mathrm{g}$ of folic acid from bread over a period of 6 hours in $200 \mu \mathrm{g}$ doses [32].

We further explored the possible mechanisms underlying the effect of high folic acid diet on NK cytotoxicity. Several factors determine the cytotoxic activity of NK cells including the percentage of NK cells, the ratio of mature to naïve NK cells and regulatory cytokines. We found no significant difference in the percentage of NK cells between diet groups, but we noted a significant reduction in the ratio of mature cytotoxic to naïve NK cells in mice fed a high folic acid diet compared to the control diet $(\mathrm{P}<0.03)$ (Fig. 3). Thus, the reduced NK cytotoxicity in mice fed the high folic acid diet could be due to impaired maturation of NK cells. The sequence of maturation of NK cells in mice is as follows: DN $>$ R1 $>$ R2 $>$ R3 [31]. DN cells have a very immature phenotype with no effector function. The difference between the diets were observed in R1 and R2 but not R3 cells, probably because R3 is the end-stage of NK cell maturation, and the experimental duration was too short to observe a difference in R3 cells.

NK cytotoxicity is governed by various cytokines, and in addition, NK cells themselves produce cytokines to regulate inflammation and infection [33-35]. The lower IL-10 production by the mice fed the high folic acid diet may also be involved in their lower NK cytotoxicity (Fig. 5). IL-10 is a pleiotropic cytokine which has immunosuppressive functions but at the same time 
increases cytotoxicity of NK cells $[36,37]$. A role for IL-10 in the lower NK cytotoxicity of the high folic acid fed mice is suggested by the fact that, the difference in NK cell cytotoxicity between the dietary groups was abolished when the splenocytes were stimulated by exogenous IL-10 prior to the NK cell assay (Fig. 6).

The mechanism by which a high folic acid diet affects the maturation of NK cells or IL-10 production is not known at present. Based on published research, we speculate that excess folic acid could regulate IL-10 expression via epigenetic mechanisms. IL-10 expression is epigenetically regulated by DNA and histone modifications and hypermethylation of the IL-10 promoter region reduces its expression [38]. In a placebo-controlled folic acid supplementation trial with a dose of $1000 \mu \mathrm{g} /$ day, higher red cell folate concentration was associated with hypermethylation of promoters in normal colonic mucosa (35). Based on these evidence, it is possible that a high folic acid diet can potentially influence IL-10 production via its effect on DNA methylation. Further studies have to be conducted to determine if the high folic acid results in hypermethylation of IL-10 promoter region.

Adequate folate nutrition is important for NK cell cytotoxicity and immune response [43, 44]. But high folic acid intake, mostly from consumption of supplements and heavily fortified foods can have negative outcomes. In recent years, many studies have reported association of high concentration of folate in plasma and multivitamin use with increased risk for breast cancer in women [45-47]. A study in rats using varying folic acid content in diets under vitamin $\mathrm{B}_{12}$ deficient conditions did not show any effect of supplemental folic acid on NK cytotoxicity [48] possibly due to the short (1 month) duration of the experimental diet and the confounding effect of vitamin $\mathrm{B}_{12}$ deficiency. Our study has provided the first evidence for linking excessive folic acid intake to impaired NK cell function. This observation is of major public health concern since the function of NK cells is immune surveillance against cancerous and pathogen infected cells. Low NK cytotoxicity has been associated with increased risk for cancer in a human study that followed-up the subjects for 11 years [19]. In this study, the NK cell cytotoxicity of the 
subjects were categorized as low, <42\%; medium, 43-58\%; and high, >58\% for men; and low, $<34 \%$; medium, 35-51\%; and high, >51\% for women, and their risk for development of cancer determined. Men and women in the low NK cell cytotoxicity group were at higher risk for development of cancer when compared to those in the medium or high groups [19]. Hence, reduction of NK cell cytotoxicity due to high folic acid intake may increase the susceptibility to cancer and viral infections especially in the elderly who are already at increased risk for these diseases.

In summary, our data show that high folic acid intake reduces NK cell cytotoxicity in old mice and this is possibly due to impairment of NK cell maturation. Our data also suggest a role for IL-10 in the observed reduction of NK cell cytotoxicity. Additional studies are needed to further determine the mechanism behind the effect of excess folic acid intake on NK cell cytotoxicity and establish its relevance to health outcomes in humans.

\section{Acknowledgements}

We thank Dr. Donald Smith for his assistance with animal care and maintenance and Mr. Alex Histed for his assistance with the NK cell cytotoxicity assays. Support from United States Department of Agriculture Specific Cooperative Agreement \#58-1950-0-014 and pilot grant from Jean Mayer USDA Human Nutrition Research Center on Aging at Tufts University. Any opinions, findings, conclusion, or recommendations expressed in this publication are those of the authors and do not necessarily reflect the view of the United States Department of Agriculture.

\section{References}

[1] Cole BF, Baron JA, Sandler RS, Haile RW, Ahnen DJ, Bresalier RS, et al. Folic acid for the prevention of colorectal adenomas: a randomized clinical trial. JAMA. 2007;297:2351-9. 
[2] Arsenault JE, Mora-Plazas M, Forero Y, Lopez-Arana S, Baylin A, Villamor E. Hemoglobin concentration is inversely associated with erythrocyte folate concentrations in Colombian school-age children, especially among children with low vitamin $\mathrm{B}_{12}$ status. Eur J Clin Nutr. 2009;63:842-9.

[3] Mikael LG, Deng L, Paul L, Selhub J, Rozen R. Moderately high intake of folic acid has a negative impact on mouse embryonic development. Birth Defects Res A Clin Mol Teratol. 2013;97:47-52.

[4] Yajnik CS, Deshpande SS, Jackson AA, Refsum H, Rao S, Fisher DJ, et al. Vitamin B 12 and folate concentrations during pregnancy and insulin resistance in the offspring: the Pune Maternal Nutrition Study. Diabetologia. 2008;51:29-38.

[5] Institute of Medicine. Food and Nutrition Board. Dietary Reference Intakes: Thiamin, Riboflavin, Niacin, Vitamin B6, Folate, Vitamin B12, Pantothenic Acid, Biotin, and Choline. Washington, DC: National Academy Press; 1998.

[6] Carmel R. Folic Acid. In: Shils M, Shike, M., Ross, A.,Caballero, B. and Cousins, R., editor. Modern Nutrition in Health and Disease. Baltimore, MD: Lippincott Williams \& Wilkins; 2005. p. 470-81.

[7] Bailey RL, Dodd KW, Gahche JJ, Dwyer JT, McDowell MA, Yetley EA, et al. Total folate and folic acid intake from foods and dietary supplements in the United States: 2003-2006. Am J Clin Nutr. 2010;91:231-7.

[8] Hodis HN, Mack WJ, Dustin L, Mahrer PR, Azen SP, Detrano R, et al. High-Dose BVitamin Supplementation and Progression of Subclinical Atherosclerosis: A Randomized Controlled Trial. Stroke. 2009;40:730-6.

[9] Bostom AG, Carpenter MA, Kusek JW, Levey AS, Hunsicker L, Pfeffer MA, et al. Homocysteine-Lowering and Cardiovascular Disease Outcomes in Kidney Transplant Recipients: Primary Results From the Folic Acid for Vascular Outcome Reduction in Transplantation Trial. Circulation. 2011;123:1763-70. 
[10] Zoungas S, McGrath BP, Branley P, Kerr PG, Muske C, Wolfe R, et al. Cardiovascular Morbidity and Mortality in the Atherosclerosis and Folic Acid Supplementation Trial (ASFAST) in Chronic Renal Failure: A Multicenter, Randomized, Controlled Trial. J Am Coll Cardiol. 2006;47:1108-16.

[11] Jamison RL, Hartigan P, Kaufman JS, et al. Effect of homocysteine lowering on mortality and vascular disease in advanced chronic kidney disease and end-stage renal disease: A randomized controlled trial. JAMA. 2007;298:1163-70.

[12] MRC. Prevention of neural tube defects: Results of the Medical Research Council Vitamin Study. Lancet. 1991;338:131-7.

[13] Centers for Disease Control and Prevention. Use of folic acid for prevention of spina bifida and other neural tube defects-1983-1991. JAMA. 1991;266:1190-1.

[14] Wilson RD, Johnson JA, Wyatt P, Allen V, Gagnon A, Langlois S, et al. Preconceptional vitamin/folic acid supplementation 2007: the use of folic acid in combination with a multivitamin supplement for the prevention of neural tube defects and other congenital anomalies. J Obstet Gynaecol Can. 2007;29:1003-26.

[15] Bailey SW, Ayling JE. The extremely slow and variable activity of dihydrofolate reductase in human liver and its implications for high folic acid intake. Proc Natl Acad Sci U S A. 2009;106:15424-9.

[16] Kalmbach RD, Choumenkovitch SF, Troen AP, Jacques PF, D'Agostino R, Selhub J. A 19-base pair deletion polymorphism in dihydrofolate reductase is associated with increased unmetabolized folic acid in plasma and decreased red blood cell folate. J Nutr. 2008;138:2323-7.

[17] Troen AM, Mitchell B, Sorensen B, Wener MH, Johnston A, Wood B, et al. Unmetabolized folic acid in plasma Is associated with reduced natural killer cell cytotoxicity among postmenopausal women. J Nutr. 2006;136:189-94.

[18] Lettau M, Schmidt H, Kabelitz D, Janssen O. Secretory lysosomes and their cargo in T and NK cells. Immunol Lett. 2007;108:10-9. 
[19] Imai K, Matsuyama S, Miyake S, Suga K, Nakachi K. Natural cytotoxic activity of peripheral-blood lymphocytes and cancer incidence: An 11-year follow-up study of a general population. Lancet. 2000;356:1795-9.

[20] Reeves PG, Nielsen FH, Fahey GC. AIN-93 purified diets for laboratory rodents: Final report of the American Institute of Nutrition ad hoc writing committee on the reformulation of the AIN-76A rodent diet. J Nutr. 1993;123:1939-51.

[21] Pickell L, Brown K, Li D, Wang X-L, Deng L, Wu Q, et al. High intake of folic acid disrupts embryonic development in mice. Birth Defects Res A Clin Mol Teratol. 2011;91:8-19.

[22] Ren Z, Pae M, Dao MC, Smith D, Meydani SN, Wu D. Dietary supplementation with tocotrienols enhances immune function in C57BL/6 mice. J Nutr. 2010;140:1335-41.

[23] McGinnes K, Chapman G, Marks R, Penny R. A fluorescence NK assay using flow cytometry. J Immunol Methods. 1986;86:7-15.

[24] Cao LF, Krymskaya L, Tran V, Mi S, Jensen MC, Blanchard S, et al. Development and application of a multiplexable flow cytometry-based assay to quantify cell-mediated cytolysis. Cytometry A. 2010;77:534-45.

[25] Beli E, Clinthorne JF, Duriancik DM, Hwang I, Kim S, Gardner EM. Natural killer cell function is altered during the primary response of aged mice to influenza infection. Mech Ageing Dev. 2011;132:503-10.

[26] Horne DW, Patterson D. Lactobacillus casei microbiological assay of folic acid derivatives in 96-well microtiter plates. Clin Chem. 1988;34:2357-9.

[27] Bradford MM. A rapid and sensitive method for the quantitation of microgram quantities of protein utilizing the principle of protein-dye binding. Anal Biochem. 1976;72:248-54.

[28] Kalmbach R, Paul L, Selhub J. Determination of unmetabolized folic acid in human plasma using affinity HPLC. Am J Clin Nutr. 2011;94:343S-7S.

[29] Hayakawa Y, Smyth MJ. CD27 dissects mature NK cells into two subsets with distinct responsiveness and migratory capacity. J Immunol. 2006;176:1517-24. 
[30] Kim S, Iizuka K, Kang H-SP, Dokun A, French AR, Greco S, et al. In vivo developmental stages in murine natural killer cell maturation. Nat Immunol. 2002;3:5238.

[31] Chiossone L, Chaix J, Fuseri N, Roth C, Vivier E, Walzer T. Maturation of mouse NK cells is a 4-stage developmental program. Blood. 2009;113:5488-96.

[32] Sweeney MR, McPartlin J, Weir DG, Daly L, Scott JM. Postprandial serum folic acid response to multiple doses of folic acid in fortified bread. Br J Nutr. 2006;95:145-51.

[33] Mocellin S, Panelli MC, Wang E, Nagorsen D, Marincola FM. The dual role of IL-10. Trends Immunol. 2003;24:36-43.

[34] Culley FJ. Natural killer cells in infection and inflammation of the lung. Immunology. 2009;128:151-63.

[35] Wang R, Jaw JJ, Stutzman NC, Zou Z, Sun PD. Natural killer cell-produced IFN- $\gamma$ and TNF- $\alpha$ induce target cell cytolysis through up-regulation of ICAM-1. J Leukoc Biol. 2012;91:299-309.

[36] Moore KW, de Waal Malefyt R, Coffman RL, O'Garra A. Interleukin-10 and the interleukin-10 receptor. Ann Rev Immunol. 2001;19:683-765.

[37] Park J, Lee S, Yoon S-R, Park Y-J, Jung H, Kim T-D, et al. IL-15-induced IL-10 increases the cytolytic activity of human natural killer cells. Mol Cells. 2011;32:265-72.

[38] Im SH, Hueber A, Monticelli S, Kang KH, Rao A. Chromatin-level regulation of the IL10 gene in T cells. J Biol Chem. 2004;279:46818-25.

[39] Purohit V, Abdelmalek MF, Barve S, Benevenga NJ, Halsted CH, Kaplowitz N, et al. Role of S-adenosylmethionine, folate, and betaine in the treatment of alcoholic liver disease: summary of a symposium. Am J Clin Nutr. 2007;86:14-24.

[40] Song Z, Barve S, Chen T, Nelson W, Uriarte S, Hill D, et al. S-adenosylmethionine (AdoMet) modulates endotoxin stimulated interleukin-10 production in monocytes. Am J Physiol Gastrointest Liver Physiol. 2003;284:G949-55. 
[41] Charles MA, Johnson IT, Belshaw NJ. Supra-physiological folic acid concentrations induce aberrant DNA methylation in normal human cells in vitro. Epigenetics. 2012;7:689-94.

[42] Christensen KE, Mikael LG, Leung K-Y, Lévesque N, Deng L, Wu Q, et al. High folic acid consumption leads to pseudo-MTHFR deficiency, altered lipid metabolism, and liver injury in mice. Am J Clin Nutr. 2015;101:646-58.

[43] Hamer DH, Sempertegui F, Estrella B, Tucker KL, Rodriguez A, Egas J, et al. Micronutrient deficiencies are associated with impaired immune response and higher burden of respiratory infections in elderly Ecuadorians. J Nutr. 2009;139:113-9.

[44] Kim YI, Hayek M, Mason JB, Meydani SN. Severe folate deficiency impairs natural killer cell-mediated cytotoxicity in rats. J Nutr. 2002;132:1361-7.

[45] Hara A, Sasazuki S, Inoue M, Shimazu T, Iwasaki M, Sawada N, et al. Use of vitamin supplements and risk of total cancer and cardiovascular disease among the Japanese general population: a population-based survey. BMC Public Health. 2011;11:540.

[46] Larsson SC, Akesson A, Bergkvist L, Wolk A. Multivitamin use and breast cancer incidence in a prospective cohort of Swedish women. Am J Clin Nutr. 2010;91:1268-72.

[47] Ericson U, Borgquist S, Ivarsson MIL, Sonestedt E, Gullberg B, Carlson J, et al. Plasma folate concentrations are positively associated with risk of estrogen receptor b negative breast cancer in a swedish nested case control study. J Nutr. 2010;140:1661-8.

[48] Partearroyo T, Ubeda N, Montero A, Achon M, Varela-Moreiras G. Vitamin B 12 and folic acid imbalance modifies NK cytotoxicity, lymphocytes B and lymphoprolipheration in aged rats. Nutrients. 2013;5:4836-48. 


\section{Figure Legends}

Fig. 1. Effect of a high folic acid diet on folate concentration in plasma and spleen of aged mice. (A) Folate forms in plasma as measured by HPLC. FA, unmetabolized folic acid; FF, formylated folates; MTHF, methyl tetrahydrofolate. (B) Total folate concentration in spleen as measured by microbial assay using Lactobacillus casei. Values are means \pm SEM, $n=10-11$ group. * $\mathrm{P}<0.01$.

Fig. 2. Effect of a high folic acid diet on NK cell cytotoxicity in aged mice. Splenocytes were isolated and incubated with YAC-1 target cells at 100:1, 50:1, 25:1, and 12.5:1 ratio of effector to target cells. Dead target cells (YAC-1 cells, CFSE+, 7-AAD+) were quantified by flow cytometry. Values are means \pm SEM, $n=10-11$ /group. $* \mathrm{P}<0.05$

Fig. 3. Effect of a high folic acid diet on percent NK cells in splenocytes in aged mice. Percent of $\mathrm{NK}\left(\mathrm{CD}^{-} \mathrm{NK} 1.1^{+}\right)$or $\mathrm{NKT}\left(\mathrm{CD}^{+} \mathrm{NK} 1.1^{+}\right)$cells in total splenocytes quantified by flow cytometry. Values are means \pm SEM, $n=10-11$ /group. $* \mathrm{P}<0.05$

Fig. 4. Effect of a high folic acid diet on NK cell subsets in splenocytes in aged mice. Splenocytes were isolated and stained with fluorescent dyes conjugated to anti-CD11b, CD27, and NK1.1 antibodies and quantified by flow cytometry. (A) Representative flow chart of NK cell subsets in spleen of a mouse. (B) NK1.1 ${ }^{+}$cells were separated into the following subsets: DN, double negative NK cells (NK cell precursors, CD11b- CD27); R1, naïve NK cells (CD11b $\left.\mathrm{CD} 27^{+}\right)$; $\mathrm{R} 2$, mature ready to kill NK cells $\left(\mathrm{R} 2: \mathrm{CD} 11 \mathrm{~b}^{+} \mathrm{CD} 27^{+}\right)$and $\mathrm{R} 3$, terminally mature predominantly cytokine producing NK cells $\left(\mathrm{CD} 11 \mathrm{~b}^{+} \mathrm{CD} 27^{-}\right)$. (B) Ratio of R2 and R3 to R1 NK cells. Values are means \pm SEM, $n=9 /$ group. $* \mathrm{P}<0.05$

Fig. 5. Cytokine secretion by splenocytes stimulated with LPS for 24 hrs. Cytokines were measured with a cytometric bead array. Values are means \pm SEM, $n=10-11$ /group. $* \mathrm{P}<0.05$

Fig. 6. Effect of a high folic acid diet on NK cell cytotoxicity after stimulation of splenocytes from aged mice with $15 \mathrm{ng} / \mathrm{mL}$ of recombinant mouse IL-10 for $15 \mathrm{hrs}$. Data shown for 25:1 
effector to target cell ratio and is similar for the 12.5:1 effector to target cell ratio (not shown). Values are means \pm SEM, $n=10-11$ /group. $* \mathrm{P}<0.05$

\section{Supplementary Figures}

Supplementary Figure 1. Effect of a high folic acid diet on T cell profile in splenocytes from aged mice. Percent T cells $\left(\mathrm{CD}^{+}\right)$, T helper cells $\left(\mathrm{CD}^{+} \mathrm{CD}^{+}\right)$, and cytotoxic T cells $\left(\mathrm{CD} 3^{+}\right.$ $\left.\mathrm{CD}^{+}\right)$in the spleen. Values are means $\pm \mathrm{SEM}, n=10-11$ /group. $* \mathrm{P}<0.05$

Supplementary Figure 2. Effect of a high folic acid diet on cytokine secretion by splenocytes from aged mice stimulated with ConA or anti-CD3 plus anti-CD28. (A) Splenocytes were stimulated with ConA $(1.5 \mu \mathrm{g} / \mathrm{mL})$ for $48 \mathrm{hrs}$ or $(\mathrm{B})$ with plate coated anti-CD3 $(5 \mu \mathrm{g} / \mathrm{mL})$ plus soluble anti-CD28 $(1 \mu \mathrm{g} / \mathrm{mL})$ for $48 \mathrm{hrs}$. Cytokines were measured with cytometric bead array. Values are means \pm SEM, $n=9-11$ /group. $* \mathrm{P}<0.05$ 
Figure(s)

\section{Figure 1}

A

-Control

- High Folic Acid

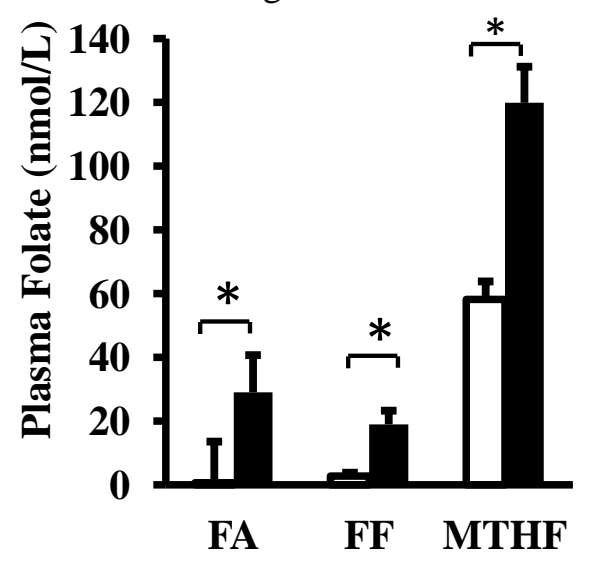

B

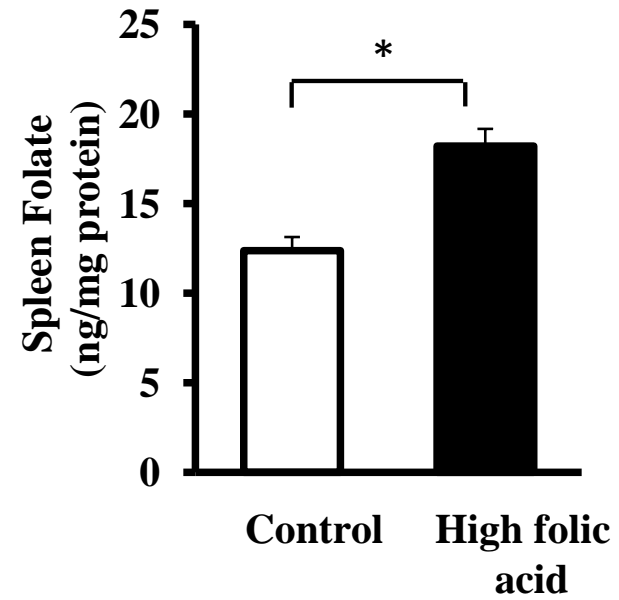




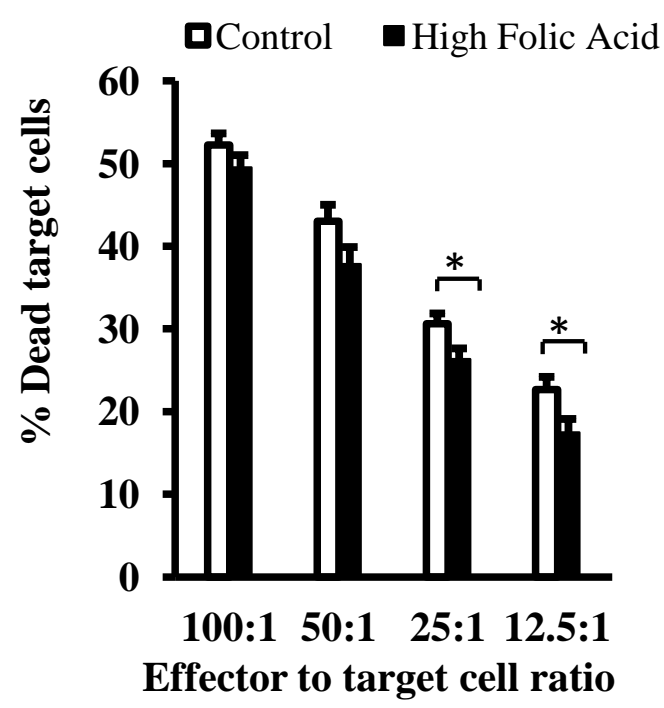




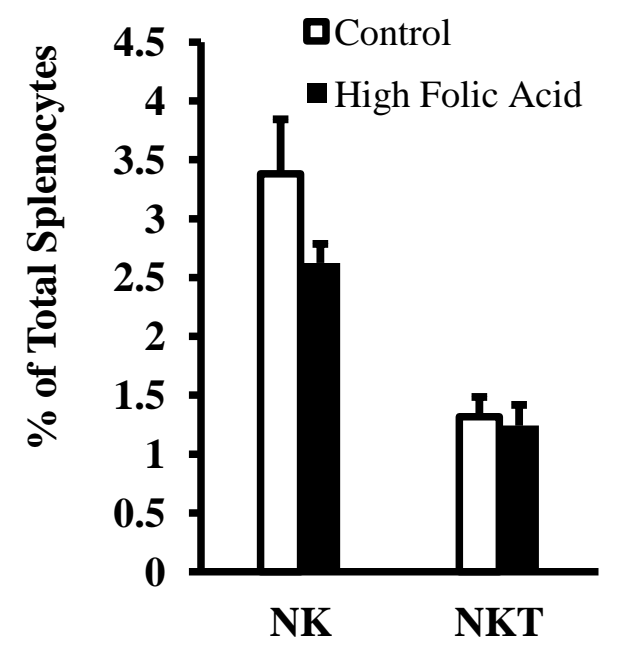



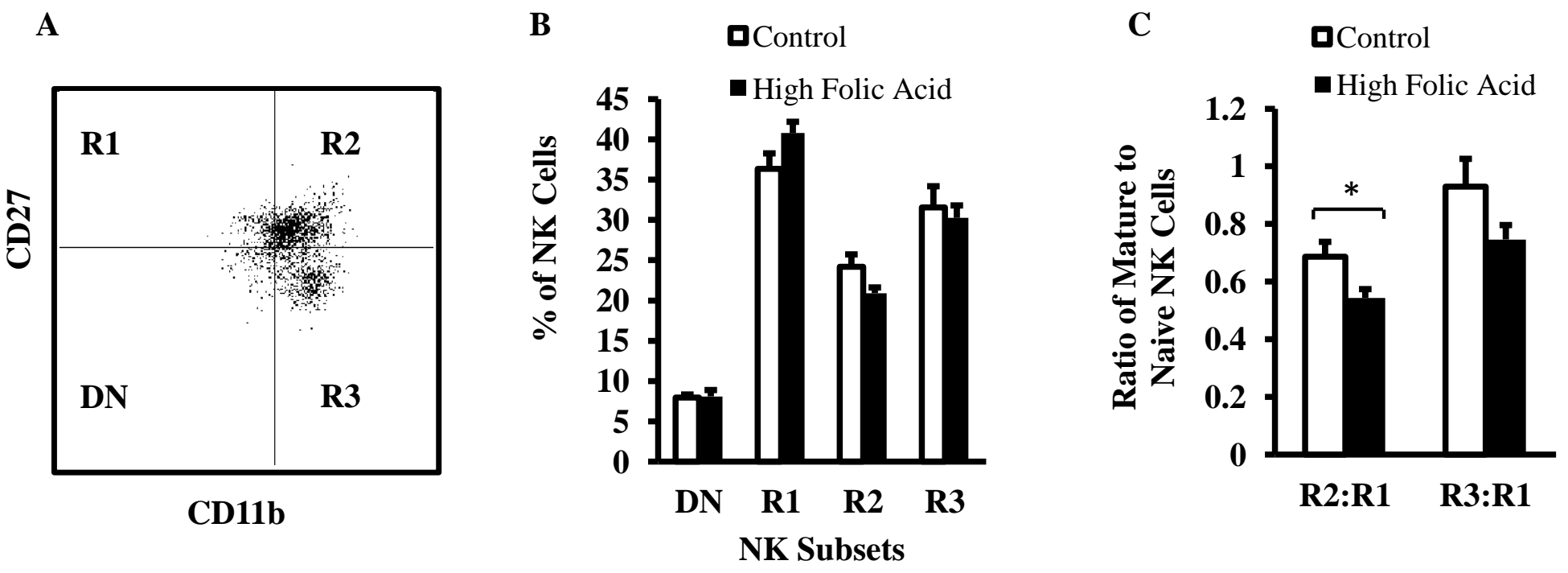


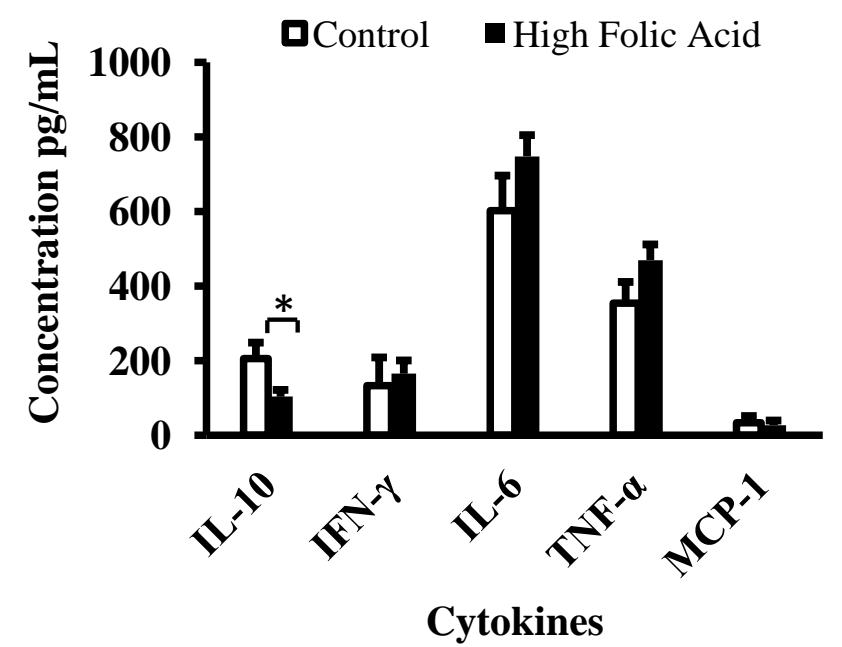




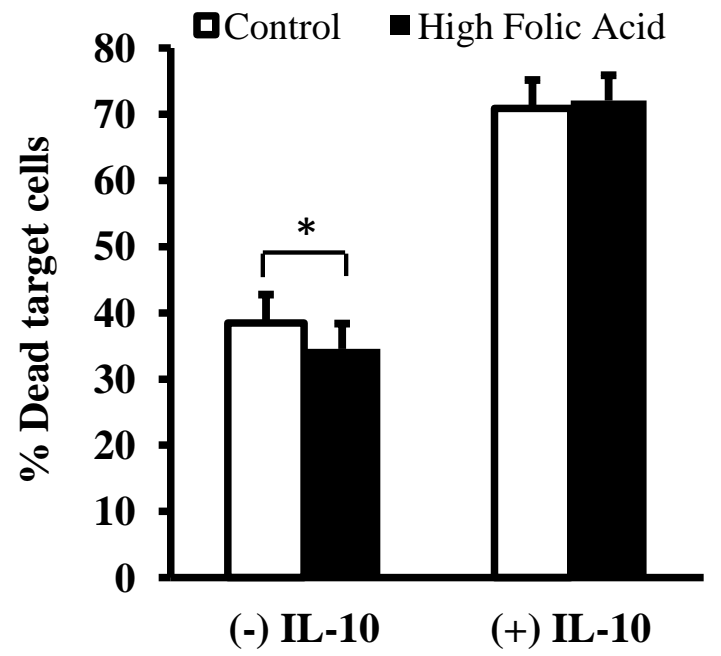

